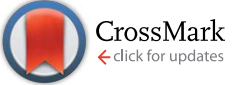

Cite this: RSC Adv., 2017, 7, 2443
Received 9th October 2016 Accepted 13th December 2016

DOI: $10.1039 / c 6 r a 24925 f$

www.rsc.org/advances

\section{High-performance ionic and non-ionic fluoropolymer/ionic liquid gel hybrid actuators based on single-walled carbon nanotubes $\uparrow$}

\begin{abstract}
Naohiro Terasawa*
The electrochemical and electromechanical properties of actuators based on an ionic fluoropolymer (Nafion ${ }^{\mathrm{TM}}$ ) and non-ionic fluoropolymer (poly(vinylidene fluoride-co-hexafluoropropylene) [PVdF(HFP)]) gel fabricated using a single-walled carbon nanotube (SWCNT) - an ionic liquid (IL) gel electrode, were compared with those of actuators based on a non-ionic fluoropolymer (PVdF(HFP)). The ionic conductivity of the Nafion ${ }^{\mathrm{TM}}$ PVdF(HFP)-IL gel electrolyte was lower than that of the PVdF(HFP)-IL gel electrolyte. We assume that an ion complex exists between the Nafion ${ }^{\mathrm{TM}} \mathrm{SO}_{3}{ }^{-}$anions and imidazolium cations but not between PVdF(HFP) and the imidazolium cations. This Nafion ${ }^{T M}-P V d F(H F P)-I L$ gel hybrid actuator mechanism resembled that of an ionic-polymer-metal composite actuator, where the IL molecules move with the IL cations and anions. The maximum strain and maximum generated stress for the Nafion ${ }^{T M}$-PVdF(HFP)-SWCNT actuator with a PVdF(HFP) : Nafion ${ }^{T M}$ ratio of $1: 3$ and a bis(trifluoromethanesulfonyl)imide-containing IL were approximately 1.6 and 1.5 times higher, respectively, than the corresponding values for the PVdF(HFP)SWCNT-IL actuator. These results indicate that ionic and non-ionic fluoropolymer-based actuators outperform non-ionic fluoropolymer-based actuators and are highly suitable for practical applications. In addition, the frequency dependence of the displacement response of the ionic and non-ionic fluoropolymer-SWCNT-IL actuator was successfully simulated using an electrochemical kinetic model. The results yielded the strain in the low-frequency limit, which was related to the electromechanical mechanism involved, and the time constant of the response, which was represented by an equivalent circuit with the ionic resistance and double-layer capacitance in series, in contrast to the non-ionic fluoropolymerSWCNT-IL actuator represented by the electronic and ionic resistance and double-layer capacitance.
\end{abstract}

\section{Introduction}

Recently, much attention has been focused on soft materials that can directly transform electrical energy into mechanical work in a wide range of applications, including robotics, tactile and optical displays, prosthetic devices, medical devices, and microelectromechanical systems. Electroactive polymers (EAPs) have many attractive characteristics that make them suitable for these applications, especially in actuators and sensors. Commonly used EAPs include conducting polymers, ${ }^{2,3}$ polyvinylidene-fluoride (PVDF)-based ferroelectric polymers, ${ }^{\mathbf{4}}$ elastomers, ${ }^{5}$ non-ionic polymers, ${ }^{6}$ and ionic polymers. Ionicpolymer-metal composites (IPMCs) have attracted significant attention in the last few years owing to their large strain capability. Several polyelectrolytes have been found to exhibit actuation properties. The most popular polyelectrolyte and ionic

Inorganic Functional Material Research Institute, National Institute of Advanced Industrial Science and Technology (AIST), 1-8-31 Midorigaoka, Ikeda, Osaka 563-8577, Japan.E-mail: terasawa-naohiro@aist.go.jp

† Electronic supplementary information (ESI) available. See DOI: $10.1039 /$ c6ra24925f fluoropolymer is Nafion ${ }^{\mathrm{TM}}$, which is commercially available from DuPont. Many investigations have focused on this polymer, studying the effects of cations on the mechanical properties and the optimisation of the morphology of metal electrodes and the stability of their mechanical properties in the electrolyte. $^{7-9}$ The results of these studies have shown that Nafion ${ }^{\mathrm{TM}}$ has very good dynamic properties as an IPMC actuator material but is not that good as a quasi-static actuator material.

However, in order for transduction to occur in Nafion ${ }^{\mathrm{TM}}$ membranes, the cations within the membrane must be mobilised by being saturated in an appropriate solvent. Water has typically been used as the solvent, owing to the favourable interaction between Nafion ${ }^{\mathrm{TM}}$ and water and the low viscosity of water. Water-swollen membranes make excellent electromechanical transducers; however, they suffer from a dramatic loss in performance when dehydrated. Efforts to retain the water inside the polymer have met with little success. Another less obvious problem associated with the use of water as a solvent is its small window of electrochemical stability. Recently, Nafion $^{\mathrm{TM}}$-ionic liquid (IL) and Nafion ${ }^{\mathrm{TM}}$-nanocarbon membrane actuators have been reported. ${ }^{\mathbf{1 0 - 1 2}}$ However, to the best of our knowledge, there have been no reports yet of a high-performance 
ionic fluoropolymer (Nafion ${ }^{\mathrm{TM}}$ )-non-ionic fluoropolymer (PVdF(HFP))-IL-nanocarbon composite membrane gel that can be made easily by the cast-film method (quantitative method).

ILs are salts containing only charged species that exist in their liquid state at room temperature. They have an immeasurably low vapour pressure and an electrochemical stability window of $4 \mathrm{~V}$ or more. ILs are used as solvents for Nafion ${ }^{\mathrm{TM}}$ transducers because they are very stable and thus eliminate the problem of solvent evaporation, allowing the use of Nafion ${ }^{\mathrm{TM}}$ transducers in a broader range of environments. Furthermore, the electrochemical stability window of most ILs is larger than that of water, allowing higher actuation voltages and thus increasing the available energy density of these devices.

We previously reported a dry actuator ${ }^{13-15}$ that can be fabricated simply by layer-by-layer casting of a 'bucky gel', ${ }^{16}$ namely, a gelatinous room-temperature IL containing single-walled carbon nanotubes (SWCNTs). The actuator has a bimorph configuration with a polymer-supported IL gel electrolyte layer sandwiched between polymer-supported bucky-gel electrode layers that allow quick and long-lasting operation in air at low applied voltages.

In earlier studies, we learned that the electromechanical and electrochemical properties of such actuators depend on the constituent anions and cations of the IL and on the type of nanocarbon and polymer used. ${ }^{17-22}$ The strain produced in the actuator was assumed to be attributable to changes in the volume of the polymer-IL gel layers in the cathode and anode. ${ }^{17}$ A simple model proposed for the actuation mechanism based on the product of the ionic transport number and the ionic volume was shown to successfully explain the actuator behaviour. ${ }^{19}$

Our group previously applied a triangular waveform voltage at various frequencies to a bucky-gel actuator to assess its voltage-current and voltage-displacement characteristics. ${ }^{15,23}$ We assumed that the frequency dependence of the actuator strain could be qualitatively modelled using an electrochemical equivalent circuit model based on the lumped resistance and capacitance of the electrode layer and the combined resistance of the gel electrolyte layer.

In the current study, we investigated the electrochemical and electromechanical properties of ionic fluoropolymer (Nafion $^{\mathrm{TM}}$ )-non-ionic fluoropolymer (PVdF(HFP))-IL gel hybrid actuators based on SWCNTs (i.e., Nafion ${ }^{\mathrm{TM}}-\mathrm{PVdF}(\mathrm{HFP})-\mathrm{IL}^{-}$ SWCNT gel hybrid actuators) and compared them with those of hybrid actuators of a non-ionic fluoropolymer (PVdF(HFP))-ILSWCNT gel. In addition, the variations in displacement with the frequency of the Nafion ${ }^{\mathrm{TM}}-\mathrm{PVdF}(\mathrm{HFP})-\mathrm{IL}-\mathrm{SWCNT}$ actuators were determined by employing a double-layered charging kinetic model, and the results were compared with those for hybrid actuators of the PVdF(HFP)-IL-SWCNT gel.

\section{Experimental}

\section{Materials}

Nafion $^{\text {TM }}$ (321-86 703 5\% Nafion ${ }^{\mathrm{TM}}$ Dispersion Solution, Wako Pure Chemical Industries Ltd., Japan) was used as received. The ILs, 1-ethyl-3-methylimidazolium tetrafluoroborate (EMI $\left[\mathrm{BF}_{4}\right]$; Fluka Chemical Corp., trademark of Honeywell Specialty
Chemicals Seelze GmbH, Sigma-Aldrich, USA) and EMI bis(trifluoromethanesulfonyl)imide (EMI[TFSI]; Merck, USA), were also used as received. The chemical structures of the ILs are shown in Fig. 1. The other reagents, SWCNTs (high-purity, $\mathrm{HiPco}^{\mathrm{TM}}$, Carbon Nanotechnologies Inc., USA), PVdF(HFP), (Kynar Flex 2801, Arkema Chemicals, Inc., Japan), methyl pentanone (Aldrich, Sigma-Aldrich, USA), propylene carbonate (Aldrich, Sigma-Aldrich, USA), and dimethylacetamide (DMAc, Kishida Chemical Co., Ltd., Japan), were all used as received.

\section{Preparation of the actuator film ${ }^{17}$}

The configuration of the bucky-gel actuator is shown in Fig. 1. The combined Nafion ${ }^{\mathrm{TM}}$ and PVdF(HFP) content was $32 \mathrm{wt} \%$, and Nafion $^{\mathrm{TM}}: \operatorname{PVdF}(\mathrm{HFP})$ weight ratios of $3: 1$ and $1: 1$ were used. The composition of the actuators was $20 \mathrm{wt} \%$ SWCNT, $48 \mathrm{wt} \% \mathrm{IL}$, and $32 \mathrm{wt} \%$ Nafion ${ }^{\mathrm{TM}}-\mathrm{PVdF}(\mathrm{HFP})$. They were prepared using the following method. First, $50 \mathrm{mg}$ of SWCNT, $120 \mathrm{mg}$ of IL, and $80 \mathrm{mg}$ of Nafion ${ }^{\mathrm{TM}}+\mathrm{PVdF}(\mathrm{HFP})$ were dispersed in $9 \mathrm{~mL}$ of DMAc by ultrasonicating the mixture for more than $5 \mathrm{~h}$. A gelatinous mixture composed of SWCNTs, IL, and Nafion ${ }^{\mathrm{TM}}-\mathrm{PVdF}(\mathrm{HFP})$ in DMAc was obtained. The electrode layer was fabricated by casting $1.6 \mathrm{~mL}$ of this gelatinous mixture in a Teflon mold $\left(2.5 \times 2.5 \mathrm{~cm}^{2}\right)$ and evaporating the solvent. The solvent was then completely removed in vacuo by heating the cast electrode layer at $80^{\circ} \mathrm{C}$. The thicknesses of the thus-obtained electrode films were 70-80 $\mu \mathrm{m}$. Gel electrolyte layers were then fabricated by casting $1 \mathrm{~mL}$ of solutions composed of one of the ILs $(100 \mathrm{mg})$ and Nafion ${ }^{\mathrm{TM}}$ $+\operatorname{PVdF}\left(\right.$ HFP) (100 mg; Nafion ${ }^{\mathrm{TM}}: \operatorname{PVdF}(\mathrm{HFP})$ ratio of $3: 1$ or $1: 1$ ) in a mixed solution composed of $2 \mathrm{~mL}$ of DMAc in a Teflon mold $\left(2.5 \times 2.5 \mathrm{~cm}^{2}\right)$, evaporating the solvent, and then completely removing it by heating in vacuo at $80{ }^{\circ} \mathrm{C}$. The thickness of the resulting gel electrolyte films was in the range of $20-30 \mu \mathrm{m}$. The actuator film was fabricated by hot pressing together the electrode and gel electrolyte films composed of the same IL. The thickness of a typical actuator film was $150-175 \mu \mathrm{m}$, which is smaller than the combined thickness of two electrode layers and one gel electrolyte layer because the thickness of each layer was reduced by hot pressing.

\section{Displacement measurement ${ }^{24}$}

The actuator experiments were conducted using an applied triangular voltage to a $10 \times 1 \mathrm{~mm}^{2}$ actuator strip clipped by two

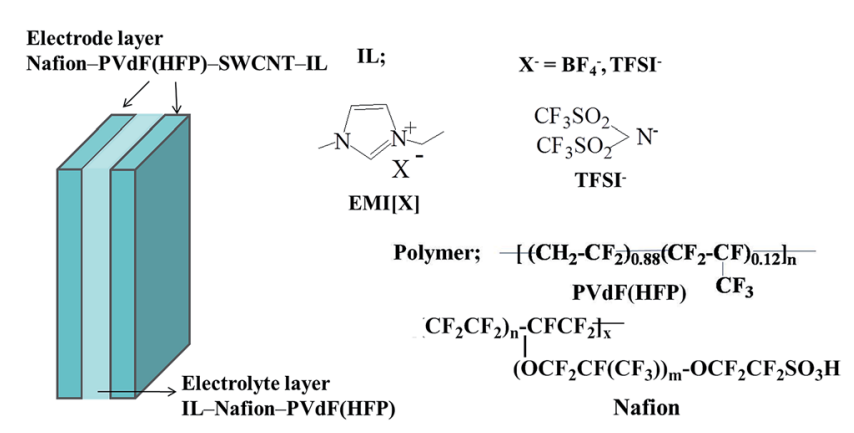

Fig. 1 Configuration of the SWCNT-IL-polymer actuator and the molecular structures of the ILs and polymers used. 
gold electrodes at $25{ }^{\circ} \mathrm{C}$ and $30 \%$ (humidity). The displacement at a point $5 \mathrm{~mm}$ away (free length) from a fixed point was continuously monitored from one side of the actuator strip using a laser displacement meter (Keyence, LC2100/2220). A potentio/galvanostat (Hokuto Denko, HA-501G) and a waveform generator (Yokogawa Electric, FC 200) were used to activate the bucky-gel actuator. The electrical parameters were simultaneously measured. Measured displacement $\delta$ was transformed into a strain difference between two bucky electrode layers $(\varepsilon)$ using the following equation on the assumption that the cross sections are planar at any position along the actuator, i.e. no distortion occurs in the cross section:

$$
\varepsilon=2 d \delta /\left(L^{2}+\delta^{2}\right),
$$

where $L$ is the free length and $d$ is the thickness of the actuator strip. $^{25}$

\section{Characterisation of the electrode and electrolyte}

All experiments was carried at $25{ }^{\circ} \mathrm{C}$ and $30 \%$ (humidity). The conductivity of the gel electrolyte layer was measured by impedance measurement using a Solarton 1250 Impedance Analyzer. The double-layer capacitance of the polymersupported bucky-gel electrode $(7 \mathrm{~mm}$ diameter) was estimated by cyclic voltammetry, which was measured with a two-electrode configuration using a potentiostat (Hokuto Denko, HSV-100). The electrical conductivities of the electrodes were evaluated using the four-probe DC current method in which a linearsweep wave of the current was applied from the outer probe electrodes, and the voltage was measured using inner probe electrodes. Current-voltage curves were obtained using a potentio/galvanostat (Hokuto Denko, HA-151) with a waveform generator (Yokogawa Electric, FC 200). The Young's moduli for the electrodes were estimated from the stress-strain curve, which was obtained using a thermal stress-strain instrument (Seiko, TMA/SS 6000).

\section{Results and discussion}

Table 1 lists the values of ionic conductivity $\kappa$ (=thickness/ $(R \times$ area)) of the Nafion ${ }^{\mathrm{TM}}-\mathrm{PVdF}(\mathrm{HFP})$-IL gel electrolyte layers. The ionic conductivities were approximately $0.4-1.1 \mathrm{mS} \mathrm{cm}^{-1}$, whereas those of the PVdF(HFP)-IL gel electrolyte layers were $1.2-2.8 \mathrm{mS} \mathrm{cm}^{-1}$. The ionic conductivity of the Nafion ${ }^{\mathrm{TM}}-$ PVdF(HFP)-IL gel electrolyte was lower than that of the PVdF(HFP)-IL gel electrolyte. In the Nafion ${ }^{\mathrm{TM}}$-PVdF(HFP)-IL gel electrolyte layers, the ionic conductivity of the $\mathrm{BF}_{4}$ anions was

Table 1 Comparison of the values of ionic conductivity $\kappa\left(\mathrm{mS} \mathrm{cm}^{-1}\right)$ of various polymer gel electrolytes and pure samples of the ILS

\begin{tabular}{llc}
\hline Electrolyte membrane & $\mathrm{BF}_{4}$ & TFSI \\
\hline PVdF(HFP)/Nafion $=1: 1$ & 1.07 & 0.74 \\
PVdF(HFP)/Nafion $=1: 3$ & 0.66 & 0.41 \\
PVdF(HFP) & 2.8 & 1.2 \\
Neat & 9.1 & 13.6
\end{tabular}

higher than that of the TFSI anions. The ionic conductivity of the gel electrolyte layer is dependent on the polymer and IL species. We assume that an ion complex is present between the $\mathrm{SO}_{3}{ }^{-}$anions of Nafion ${ }^{\mathrm{TM}}$ and the imidazolium cations, whereas no ion complex exists between $\mathrm{PVdF}(\mathrm{HFP})$ and the imidazolium cations (Fig. 2). In addition, it is well known that especially the composite for Nafion ${ }^{\mathrm{TM}}$ and hydrophilic ILs both are highly sensitive to temperature and humidity changes, ${ }^{26,27}$ however, there was little affected by temperature; $20{ }^{\circ} \mathrm{C}$ and humidity; $30 \%$ in this system.

Table 2 lists the values of the double-layer capacitance $C$ [gravimetric capacitance of the SWCNTs, $C_{\mathrm{SWCNT}}=C_{1} /$ (weight of the SWCNTs)] of the polymer-supported bucky-gel electrodes. At a slow sweep rate $\left(1 \mathrm{mV} \mathrm{s}^{-1}\right)$, the specific capacitance of the Nafion $^{\mathrm{TM}}-\mathrm{PVdF}(\mathrm{HFP})$-SWCNT-EMI $\left[\mathrm{BF}_{4}\right]$ electrodes was as high as 71-142 $\mathrm{F} \mathrm{g}^{-1}$, whereas that of the Nafion ${ }^{\mathrm{TM}}-\mathrm{PVdF}(\mathrm{HFP})-$ SWCNT-EMI[TFSI] electrodes was 31-64 $\mathrm{F} \mathrm{g}^{-1}$. The double-layer capacitance of the $\mathrm{BF}_{4}$ anions was larger than that of the TFSI anions. The double-layer capacitance depends on the IL species. We assume that the size of the ions (the van der Waals volume) decreased in the order TFSI $>\mathrm{EMI}>\mathrm{BF}_{4} ;{ }^{15}$ therefore, the number of $\mathrm{BF}_{4}$ anions and imidazolium cations in the doublelayer capacitance was larger than that of the TFSI anions and imidazolium cations. The double-layer capacitance of the IL gel electrode with a content ratio of $\mathrm{PVdF}(\mathrm{HFP}):$ Nafion $^{\mathrm{TM}}=1: 3$ was larger than that of the IL gel electrode with a ratio of $\operatorname{PVdF}(\mathrm{HFP}): \mathrm{Nafion}^{\mathrm{TM}}=1: 1$. We assume that an ion complex exists between the $\mathrm{SO}_{3}{ }^{-}$anions of Nafion ${ }^{\mathrm{TM}}$ and the imidazolium cations, whereas no ion complex exists between $\operatorname{PVdF}(\mathrm{HFP})$ and the imidazolium cations (Fig. 2).

Table $\mathrm{S} 1 \uparrow$ lists the electrical conductivities of the polymer gel electrode layers containing ILs (EMI[BF $\left.{ }_{4}\right]$ and EMI[TFSI]). The electrical conductivities of the Nafion ${ }^{\mathrm{TM}}-\mathrm{PVdF}(\mathrm{HFP})-\mathrm{SWCNT}-$ $\mathrm{EMI}\left[\mathrm{BF}_{4}\right]$ electrodes were as high as $20-23 \mathrm{~S} \mathrm{~cm}^{-1}$, whereas those of the Nafion ${ }^{\mathrm{TM}}$-PVdF(HFP)-SWCNT-EMI[TFSI] electrodes were $24-25 \mathrm{~S} \mathrm{~cm}^{-1}$. The electrical conductivity of the TFSI anions was higher than that of the $\mathrm{BF}_{4}$ anions. Thus, the electrical
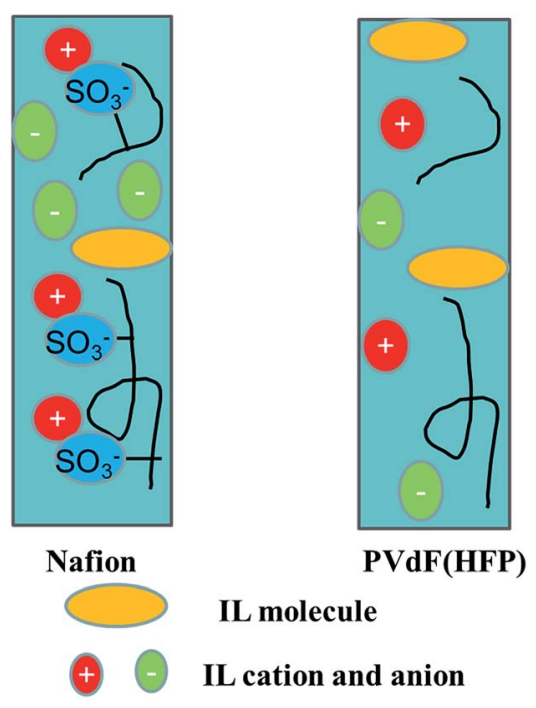

\section{IL molecule}

\section{IL cation and anion}

Fig. 2 Schematic illustration of the Nafion ${ }^{T M}$ or PVdF(HFP)-IL gel. 
Table 2 Comparison of the values of gravimetric capacitance $C\left(\mathrm{~F} \mathrm{~g}^{-1}\right)$ of various SWCNT-based polymer gel electrode layers containing an IL (EMI[BF 4 or EMI[TFSI]) (applied voltage: $\pm 0.5 \mathrm{~V}$ with a triangular waveform; sweep rate $=1 \mathrm{mV} \mathrm{s}^{-1}$ )

\begin{tabular}{|c|c|c|c|c|}
\hline Electrode-electrolyte membrane & $\begin{array}{l}\mathrm{PVdF}(\mathrm{HFP}) / \\
\text { Nafion }=1: 1\end{array}$ & $\begin{array}{l}\text { PVdF(HFP)/ } \\
\text { Nafion }=1: 3\end{array}$ & $\begin{array}{l}\text { PVdF(HFP)/ } \\
\text { Nafion }=1: 1\end{array}$ & $\begin{array}{l}\text { PVdF(HFP)/ } \\
\text { Nafion }=1: 3\end{array}$ \\
\hline PVdF(HFP)/Nafion-PVdF(HFP)/Nafion & 97.2 & 116.6 & 51.3 & 63.9 \\
\hline PVdF(HFP)/Nafion-PVdF(HFP) & 70.6 & 97.9 & 51.9 & 60.1 \\
\hline PVdF(HFP)-PVdF(HFP)/Nafion & 142.3 & 176.1 & 22.9 & 31.1 \\
\hline
\end{tabular}

conductivity of this gel electrode layer was dependent on the IL anions. On the other hand, the electrical conductivity of the PVdF(HFP)-SWCNT-IL layer was 16-17 $\mathrm{S} \mathrm{cm}^{-1}$, which was lower than that of the Nafion ${ }^{\mathrm{TM}}-\mathrm{PVdF}(\mathrm{HFP})-$ SWCNT-IL layer.

Fig. 3 shows the strain produced in the actuators (electrodegel electrolyte) as a function of the frequency of the applied voltage, which was $\pm 2 \mathrm{~V}$ and had a triangular waveform (Nafion $^{\mathrm{TM}}: \mathrm{PVdF}(\mathrm{HFP})$ ratio $\left.=1: 1 ; \mathrm{IL} ;\left[\mathrm{BF}_{4}\right]\right)$. The strain exhibited a clear dependence on the voltage frequency. At low frequencies (i.e., 0.05-0.005 Hz), the SWCNTs dispersed in the electrode layer were considered to be fully charged. In contrast, at higher frequencies, the time available was not sufficient for complete charging to occur. In addition, in the case of the other IL and Nafion ${ }^{\mathrm{TM}}: \operatorname{PVdF}(\mathrm{HFP})$ with a ratio of $1: 3$, the strain showed the same tendency.

Table 3 lists the maximum strain, calculated from the peakto-peak displacements, of the SWCNT-based actuators with the following electrode-gel electrolyte combinations: PVdF(HFP)/Nafion ${ }^{\mathrm{TM}}$-PVdF(HFP)/Nafion ${ }^{\mathrm{TM}}, \quad$ PVdF(HFP)/ Nafion ${ }^{\mathrm{TM}}-\mathrm{PVdF}$ (HFP), PVdF(HFP)- PVdF(HFP)/Nafion ${ }^{\mathrm{TM}}$, and PVdF(HFP)-PVdF(HFP). The strain values are shown as functions of the frequency of the applied voltage $( \pm 2 \mathrm{~V}$ and triangular waveform). In the case where Nafion ${ }^{\mathrm{TM}}$ was the electrode or gel electrolyte or both, the maximum strain was $0.28-0.54 \%$ for the $\mathrm{BF}_{4}$-containing $\mathrm{IL}$ and $0.18-0.45 \%$ for the TFSIcontaining IL. In particular, for the $\mathrm{BF}_{4}$-containing IL, the maximum strain of the actuator with $\mathrm{PVdF}(\mathrm{HFP}) / \mathrm{Nafion}^{\mathrm{TM}}$ as

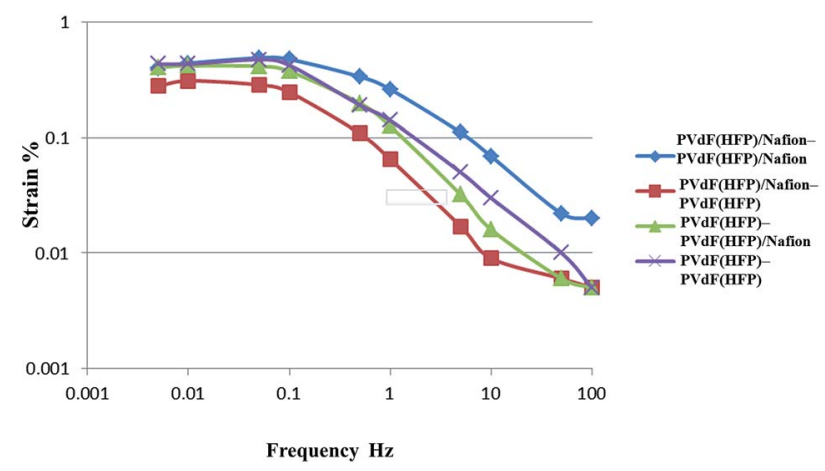

Fig. 3 Strain, as calculated from the peak-to-peak displacements, generated in SWCNT-based actuators [PVdF(HFP) : Nafion ${ }^{\mathrm{TM}}$ ratio $=$ 1 : 1, with $P V d F(H F P) / N a f i o T^{T M}$ as the electrode and gel electrolyte] that containing an IL (EMI[BF $\left.\left.F_{4}\right]\right)$ as functions of the frequency of the applied voltage ( $\pm 2 \vee$ and triangular waveform). the electrode and gel electrolyte (0.49-0.54\%) was larger than that for the actuator with PVdF(HFP) as both electrode and electrolyte. In addition, for the TFSI-containing $\mathrm{IL}$, the maximum strains of the PVdF(HFP)/Nafion ${ }^{\mathrm{TM}}-\mathrm{PVdF}(\mathrm{HFP}) /$ Nafion $^{\mathrm{TM}}$ and the $\mathrm{PVdF}(\mathrm{HFP}) / \mathrm{Nafion}^{\mathrm{TM}}-\mathrm{PVdF}(\mathrm{HFP})$ (0.31$0.45 \%$ ) actuators were larger than that of the PVdF(HFP)PVdF(HFP) actuator. This could be because the mechanism of these Nafion ${ }^{\mathrm{TM}}$ actuators was similar to that of the IPMC actuator (Fig. 3), in which the IL molecules move with the IL cations and anions. In the other case, although the mechanism was similar to that of the IPMC actuator, other factors were involved as well. In the case of the $\mathrm{BF}_{4}$-containing $\mathrm{IL}$, the maximum strain of the PVdF(HFP)/Nafion ${ }^{\mathrm{TM}}-\mathrm{PVdF}(\mathrm{HFP}) / \mathrm{Nafion}^{\mathrm{TM}}$ actuator with a PVdF(HFP) : Nafion ${ }^{\mathrm{TM}}$ ratio of $1: 3$ was approximately 1.3 times higher than that of the PVdF(HFP)-PVdF(HFP) actuator. In the case of the TFSI-containing IL, the maximum strain of the PVdF(HFP)/Nafion ${ }^{\mathrm{TM}}-\mathrm{PVdF}(\mathrm{HFP})$ actuator with a PVdF(HFP) : Nafion ${ }^{\mathrm{TM}}$ ratio of $1: 3$ was approximately 1.6 times higher than that of the PVdF(HFP)-PVdF(HFP) actuator. These results indicate that $\mathrm{PVdF}(\mathrm{HFP}) / \mathrm{Nafion}^{\mathrm{TM}}$-based actuators outperformed PVdF(HFP)-based actuators.

In addition, it is well known that especially the composite for Nafion $^{\mathrm{TM}}$ and hydrophilic ILs both are highly sensitive to temperature and humidity changes. ${ }^{26,27}$ However, there was little affected by temperature; $25{ }^{\circ} \mathrm{C}$ and humidity; $50 \%$ in this measurement time range.

We previously proposed a mechanism to account for the bending observed in the type of actuators investigated in the present study. ${ }^{14}$ When a voltage was applied between the two electrodes, the cations and anions in the gel electrolyte layer migrated to the cathode and anode layers, respectively, and an electric double layer was formed with negatively and positively charged nanotubes. This type of ion transport likely resulted in the swelling of the cathode layer and shrinkage of the anode layer. In this system, the ionicity of $\mathrm{EMI}\left[\mathrm{BF}_{4}\right]$ was 0.66 , while that of EMI[TFSI] was $0.60 .{ }^{28}$ Therefore, not all ILs were dissociated. We previously proposed the above mechanism for the present Nafion $^{\mathrm{TM}}$-PVdF(HFP) actuator. Moreover, this mechanism is similar to that of an IPMC actuator (Fig. 4), in which the IL molecules move with the IL cations and anions. It has been reported that in polymer-IL composite electrochemical artificial muscles, bending occurs owing to ion transfer near the electrode. Furthermore, the direction of bending strongly depends on the ionic transport number. ${ }^{19}$ In the present study, the sizes of the investigated ions decrease in the order TFSI $>\mathrm{EMI}>\mathrm{BF}_{4}$; 
Table 3 Comparison of the maximum strain (\%) generated in the SWCNT-based polymer actuators that contains an IL (EMI[BF $]$ or EMI[TFSI])

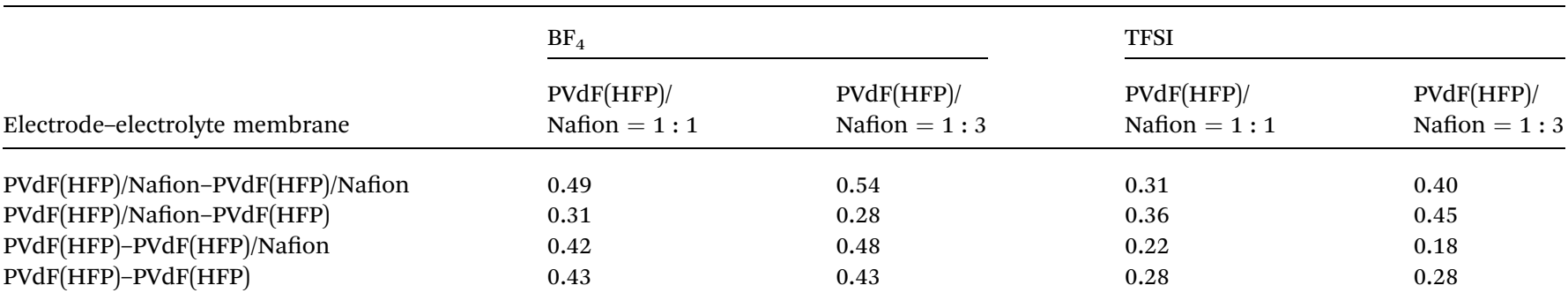

however, on the basis of the results in Table $S 2, \dagger$ the ionic transport numbers $t_{+}\left(=D_{+} /\left(D_{+}+D_{-}\right)\right)$and $t_{-}\left(=D_{-} /\left(D_{+}+D_{-}\right)\right)$ were larger for the EMI cations than for the TFSI or $\mathrm{BF}_{4}$ anions. Consequently, the actuator bent towards the anode side. In addition, it might be also appropriate here to go forward with the two-carrier model, proposed by Liu and Kruusamäe. ${ }^{29,30}$

Previous studies ${ }^{15,23}$ have investigated the voltage-current and voltage-displacement relationships of a bucky-gel actuator under a voltage with a triangular waveform applied at various frequencies. In those studies, both the time constant of the response and the low-frequency limit strain could be predicted in this fashion.

Surprisingly, Fig. 5 clearly shows that the frequency dependence of the strain is well reproduced by Curve A. Furthermore, Fig. 5 clearly shows that the frequency dependence of the strain is reproduced by the double-layer charging kinetic model when we consider only the gel electrolyte resistance, which is different from the case of the PVdF(HFP)-SWCNT-EMI $\left[\mathrm{BF}_{4}\right]$ device (Curve B), where the electrode and gel electrolyte resistance are considered. Similar results were obtained for the PVdF(HFP)Nafion ${ }^{\mathrm{TM}}$-SWCNT-EMI[TFSI] device with a PVdF(HFP) : Nafion ${ }^{\mathrm{TM}}$ ratio of $1: 3$ and the PVdF(HFP)-Nafion ${ }^{\mathrm{TM}}-\mathrm{SWCNT}-\mathrm{IL}$ device with a $\mathrm{PVdF}(\mathrm{HFP}):$ Nafion $^{\mathrm{TM}}$ ratio of $1: 1$.
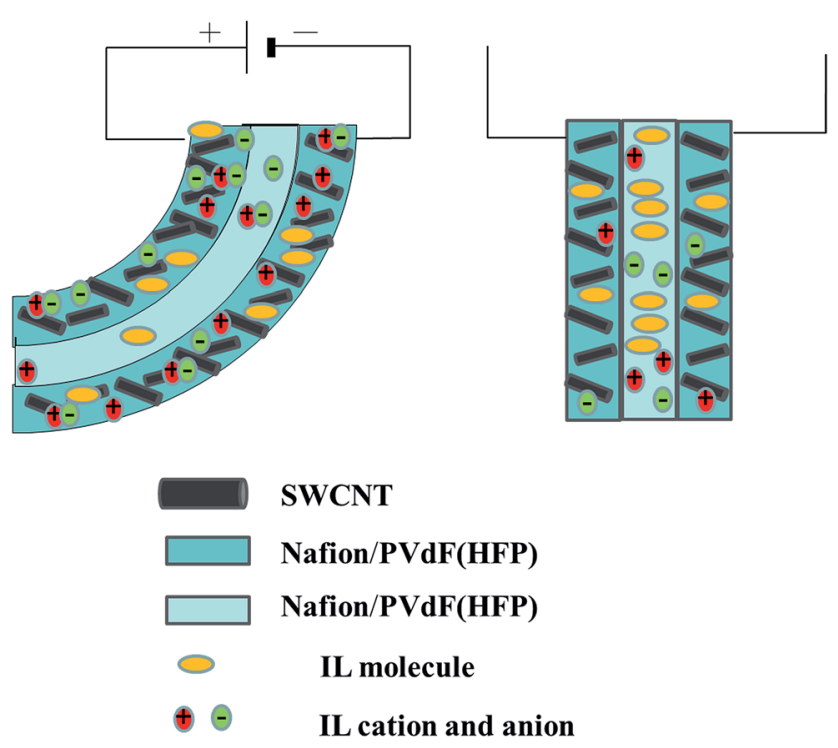

Fig. 4 Schematic illustration of the response model of the actuators based on an IL ion and molecule transfer mechanism similar to that of an IPMC actuator.
To optimise the performance of the actuator, the results summarised in Tables S3 and $\mathrm{S} 4 \uparrow$ should be considered with respect to both kinetic and static components. From the kinetic viewpoint, the frequency dependence of the strain was determined by electrochemical charging, as shown in Fig. 5. Obtaining good fits generally requires considering the electrode resistance. The response of the PVdF(HFP)-Nafion ${ }^{\mathrm{TM}}$-SWCNTIL polymer actuators could be improved by fabricating a gel electrolyte with a higher ionic conductivity, which is different from the case of the PVdF(HFP)-SWCNT-IL device. ${ }^{15}$

Table S5 $\uparrow$ compares the Young's moduli of the different actuators investigated in the present study. The Young's moduli were 142-143 MPa for the Nafion ${ }^{\mathrm{TM}}$-PVdF(HFP)-SWCNT-EMI $\left[\mathrm{BF}_{4}\right]$ actuator and 120-122 MPa for the Nafion ${ }^{\mathrm{TM}}-\mathrm{PVdF}(\mathrm{HFP})-$ SWCNT-EMI[TFSI] actuator, which are consistent with the formation of an open mesoporous network. ${ }^{20}$ Because the values of the Young's modulus of the Nafion ${ }^{\mathrm{TM}}-\mathrm{PVdF}(\mathrm{HFP})-$ SWCNT-EMI $\left[\mathrm{BF}_{4}\right]$ actuator were larger than those of the Nafion $^{\mathrm{TM}}$-PVdF(HFP)-SWCNT-EMI[TFSI] actuator, we can assume that the Young's modulus of polymer-based actuators is dependent on the type of IL used.

Table 4 lists the maximum stress $(\sigma)$ generated in the polymer-supported bucky-gel actuators. The maximum stress generated during actuation was calculated using Hooke's law, i.e., $\sigma=Y \times \varepsilon_{\max }$, where $\varepsilon_{\max }$ is the maximum strain and $Y$ is the Young's modulus. The maximum generated stresses were 0.40-

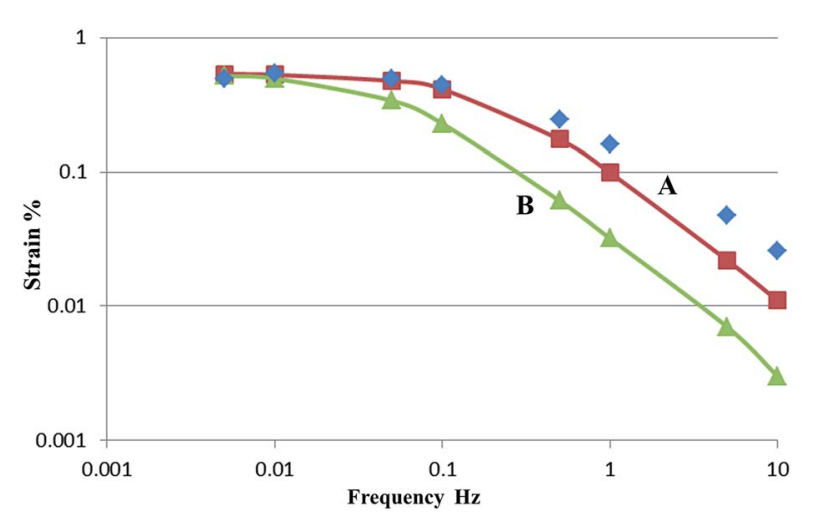

Fig. 5 (Blue symbols) Measured and (Curves A and B) simulated results showing the frequency dependence of the strain of the PVdF(HFP)Nafion ${ }^{\mathrm{TM}}-\mathrm{SWCNT}-\mathrm{EMI}^{\mathrm{B}}\left[\mathrm{BF}_{4}\right]$ device with $\mathrm{PVdF}(\mathrm{HFP})$ : Nafion ${ }^{\mathrm{TM}}$ ratio of $1: 3$. Curve $A$ was calculated using the equivalent circuit shown in Fig. S1(b). $\dagger$ Curve B was calculated using the equivalent circuit shown in Fig. S1(c). $\dagger$ 
Table 4 Comparison of the maximum stress (MPa) generated in different actuators

\begin{tabular}{|c|c|c|c|c|}
\hline Electrode-electrolyte membrane & \multicolumn{2}{|l|}{$\mathrm{BF}_{4}$} & \multicolumn{2}{|l|}{ TFSI } \\
\hline PVdF(HFP)/Nafion-PVdF(HFP)/Nafion & 0.69 & 0.77 & 0.37 & 0.48 \\
\hline PVdF(HFP)/Nafion-PVdF(HFP) & 0.44 & 0.40 & 0.44 & 0.54 \\
\hline PVdF(HFP)-PVdF(HFP)/Nafion & 0.73 & 0.84 & 0.29 & 0.23 \\
\hline
\end{tabular}

0.84 MPa in the Nafion ${ }^{\mathrm{TM}}-\mathrm{PVdF}(\mathrm{HFP})-\mathrm{SWCNT}_{\mathrm{EMI}}\left[\mathrm{BF}_{4}\right]$ actuator and 0.23-0.54 MPa in the Nafion ${ }^{\mathrm{TM}}-\mathrm{PVdF}(\mathrm{HFP})-\mathrm{SWCNT}-$ EMI[TFSI] actuator. In particular, in the TFSI-containing IL, the maximum generated stress of the actuator with a $\operatorname{PVdF}(\mathrm{HFP}) /$ Nafion ${ }^{\mathrm{TM}}$ electrode, a PVdF(HFP) gel electrolyte actuator, and a PVdF(HFP) : Nafion ${ }^{\mathrm{TM}}$ content ratio of $1: 3$ was approximately 1.5 times higher than that of the actuator with a PVdF(HFP) electrode and gel electrolyte. In the actuator with a PVdF(HFP)/ Nafion ${ }^{\mathrm{TM}}$ electrode and gel electrolyte, the maximum stress generated was approximately 1.3 times higher than that in the actuator with a PVdF(HFP) electrode and gel electrolyte. These results indicate that $\mathrm{PVdF}(\mathrm{HFP}) / \mathrm{Nafion}^{\mathrm{TM}}{ }^{\mathrm{M}}$-based actuators can outperform PVdF(HFP)-based actuators.

\section{Conclusions}

The electrochemical and electromechanical properties of ionic fluoropolymer (Nafion $^{\mathrm{TM}}$ ) and non-ionic fluoropolymer (PVdF(HFP))-based actuators fabricated using a SWCNT-IL gel electrode were compared with those of actuators based on a non-ionic fluoropolymer (PVdF(HFP)). The ionic conductivity of the Nafion ${ }^{\mathrm{TM}}-\mathrm{PVdF}(\mathrm{HFP})$-IL gel electrolyte was lower than that of the PVdF(HFP)-IL gel electrolyte. We assume that an ion complex exists between the $\mathrm{SO}_{3}{ }^{-}$anions of Nafion ${ }^{\mathrm{TM}}$ and the imidazolium cations, whereas no ion complex is present between PVdF(HFP) and the imidazolium cations. The doublelayer capacitance depended on the IL species. We assume that the ion size (van der Waals volume) decreases in the order TFSI $>\mathrm{EMI}>\mathrm{BF}_{4}$; therefore, the number of $\mathrm{BF}_{4}$ anions and cations in the double-layer was larger than that of the TFSI anions.

The maximum strains of the $\mathrm{PVdF}(\mathrm{HFP}) / \mathrm{Nafion}^{\mathrm{TM}}{ }_{-}$ $\mathrm{PVdF}(\mathrm{HFP}) / \mathrm{Nafion}^{\mathrm{TM}}$ actuator with $\mathrm{BF}_{4}$-containing IL and the PVdF(HFP)/Nafion ${ }^{\mathrm{TM}}-\mathrm{PVdF}$ (HFP)/Nafion ${ }^{\mathrm{TM}}$ and $\mathrm{PVdF}(\mathrm{HFP}) /$ Nafion $^{\mathrm{TM}}-\mathrm{PVdF}(\mathrm{HFP})$ actuators with TFSI-containing IL were larger than that of the actuator with $\operatorname{PVdF}(\mathrm{HFP})$ as both the electrode and electrolyte because this $\mathrm{PVdF}(\mathrm{HFP}) / \mathrm{Nafion}^{\mathrm{TM}}$ actuator mechanism is similar to that of an IPMC actuator in which the IL molecules move with the IL cations and anions. The maximum strain and maximum generated stress of the PVdF(HFP)/Nafion ${ }^{\mathrm{TM}}$-PVdF(HFP) actuator with a PVdF(HFP) : Nafion ${ }^{\mathrm{TM}}$ ratio of $1: 3$ and a TFSI-containing IL were approximately 1.6 and 1.5 times higher than those of the PVdF(HFP)-PVdF(HFP) actuator, respectively. These results indicate that PVdF(HFP)/Nafion ${ }^{\mathrm{TM}}$-based actuators can outperform PVdF(HFP)-based actuators and are highly suitable for practical applications.
The frequency dependence of the displacement response of non-ionic and ionic fluoropolymer ( $\mathrm{PVdF}(\mathrm{HFP}) / \mathrm{Nafion}^{\mathrm{TM}}{ }_{-}$ SWCNT-IL) actuators was measured and successfully simulated using a double-layered charging kinetic model. The results yielded the strain in the low-frequency limit, which is related to the electromechanical mechanism involved. The time constant of the response was also obtained and represented by an equivalent circuit composed of a series combination of the ionic resistance and double-layer capacitance, in contrast to that of the non-ionic (fluoropolymer PVdF(HFP))-SWCNT-IL actuator, which is represented by the electronic and ionic resistance and double-layer capacitance.

\section{Acknowledgements}

This work was partly supported by the KAKENHI Grant-in Aid for Scientific Research C (No. 24550264) from JSPS.

\section{Notes and references}

1 Y. Bar-Cohen, Directions for development of the field of Electroactive Polymer (EAP), Proc. SPIE 7976, Electroactive Polymer Actuators and Devices (EAPAD), 2011, p. 797604, DOI: $10.1117 / 12.880056$.

2 E. Smela, Adv. Mater., 2003, 15, 481-494.

3 L. Bay, K. West, P. Sommer-Larsen, S. Skaarup and M. Benslimane, Adv. Mater., 2003, 15, 310-313.

4 G. T. Davis, T. Furukawa, A. J. Lovinger and M. G. Broadhurst, Macromolecules, 1982, 15, 329-333.

5 R. Pelrine, R. Kornbluh, Q. Pei and J. Joseph, Science, 2000, 287, 836-839.

6 J. M. Zheng, M. Watanabe, H. Shirai and T. Hirai, Chem. Lett., 2000, 5, 500-501.

7 K. J. Kim and M. Shahinpoor, Smart Mater. Struct., 2003, 12, 65-79.

8 B. Akle, D. J. Leo, M. A. Hickner and J. E. McGrath, J. Mater. Sci., 2005, 40, 3715-3724.

9 S. N. Nasser and Y. Wu, J. Appl. Phys., 2003, 93, 5255-5267. 10 M. Bennett and D. Leo, Sens. Actuators, A, 2004, 115, 79-90.

11 B. J. Akle, M. D. Bennett and D. J. Leo, Proc. SPIE, 2005, 5759, 153-164.

12 L. Sheng, Y. Li, H. Cebeci, R. G. de Villoria, J.-H. Lin, B. L. Wardle and Q. M. Zhang, Adv. Funct. Mater., 2010, 20, 3266-3271.

13 T. Fukushima, K. Asaka, A. Kosaka and T. Aida, Angew. Chem., Int. Ed., 2005, 44, 2410-2413. 
14 K. Mukai, K. Asaka, K. Kiyohara, T. Sugino, I. Takeuchi, T. Fukushima and T. Aida, Electrochim. Acta, 2008, 53, 5555-5562.

15 I. Takeuchi, K. Asaka, K. Kiyohara, T. Sugino, K. Mukai, T. Fukushima and T. Aida, Electrochim. Acta, 2009, 53, 1762-1768.

16 T. Fukushima, A. Kosaka, Y. Ishimura, T. Yamamoto, T. Takigawa, N. Ishii and T. Aida, Science, 2003, 300, 20722074.

17 N. Terasawa, I. Takeuchi and H. Matsumoto, Sens. Actuators, $B, 2009$, 139, 624-630.

18 N. Terasawa, I. Takeuchi, H. Matsumoto, K. Mukai and K. Asaka, Sens. Actuators, B, 2011, 156, 539-545.

19 N. Terasawa and K. Asaka, Sens. Actuators, B, 2014, 193, 851856.

20 I. Takeuchi, K. Asaka, K. Kiyohara, T. Sugino, N. Terasawa, K. Mukai and S. Shiraishi, Carbon, 2009, 47, 1373-1380.

21 N. Terasawa, N. Ono, Y. Hayakawa, K. Mukai, T. Koga, H. Higashi and K. Asaka, Sens. Actuators, B, 2011, 160, 161-167.
22 N. Terasawa, Y. Hayashi, T. Koga, H. Higashi and K. Asaka, Sens. Actuators, B, 2014, 202, 382-387.

23 N. Terasawa and I. Takeuchi, Electrochim. Acta, 2014, 123, 340-345.

24 N. Terasawa and I. Takeuchi, Sens. Actuators, B, 2010, 145, 775-780.

25 Q. Pei and O. Inganas, J. Phys. Chem., 1992, 96, 10507-10514. 26 I. Must, U. Johanson, F. Kaasik, I. Põldsalu, A. Punning and A. Aabloo, Phys. Chem. Chem. Phys., 2013, 15, 9605-9614.

27 I. Must, V. Vunder, F. Kaasik, I. Põldsalu, U. Johanson, A. Punning and A. Aabloo, Sens. Actuators, B, 2014, 202, 114-122.

28 S. Tsuzuki, H. Tokuda, K. Hayamizu and M. Watanabe, J. Phys. Chem. B, 2005, 109, 16474-16481.

29 Y. Liu, S. Liu, J. Lin, D. Wang, V. Jain, R. Montazami, J. R. Heflin, J. Li, L. Madsen and Q. M. Zhang, Appl. Phys. Lett., 2010, 96, 223503.

30 K. Kruusamäe, T. Sugino and K. Asaka, J. Appl. Phys., 2015, 118, 014502. 